\title{
A 4-DOF Robotic Arm - Kinematics and Implementation as Case Study in Laboratory Environment
}

\author{
M. Papoutsidakis \\ Dept. of Automation \\ Engineering \\ PUAS, Athens, Greece
}

\author{
A. Chatzopoulos \\ Dept. of Automation \\ Engineering \\ PUAS, Athens, Greece
}

\author{
D. Piromalis \\ Dept. of Automation \\ Engineering \\ PUAS, Athens, Greece
}

\author{
D. Tseles \\ Dept. of Automation \\ Engineering \\ PUAS, Athens, Greece
}

\begin{abstract}
This paper describes briefly the construction of a 4 DOF robotic arm and depicts the research, construction and function of the robotic arm and its components. The system has two basic functions. At the automatic function the arm moves an object between to positions. During the manual function a user can control the arm and transport the object using buttons, switches, potentiometers and a joystick. At this function the user can save random position of the arm in memory of the Arduino platform. Then the system is waiting till the proper command is given and moves the robotic arm from point to point as they defined by the user. Moreover forward kinematics equations has been researched and resolved for the system.
\end{abstract}

Keywords

Robotic Arm

\section{INTRODUCTION}

\section{Term of robotics and robot}

Robotics is a modern scientific sector that deals with the research, design, construction, development and applications of the robots. The purpose of the robots is to replace the humans in difficult and harmful tasks.

The advantages of the robots are the flexibility, speed, adaptation to various processes and the option of reprogramming to change their operation depending on the application requirements..

The term "Robot" invented by a Czech author Karel Capek, who used this term on his book "Rossum's Universal Robots". Capek inspired that term by the Czech word "robota" which means hard labor.

Another author namely Russian Isaac Asimov invented the term "Robotics" to explain the science that deals with robots. Asimov describes the robots as humanoid machine free of emotions which may be programmed by a human user.

At 1954 G.C.Devol used the term "Industrial Robot" in order to describe a controlled mechanical arm that can execute several works in the industry and replace the human.

\section{Historical facts}

Exempting form various manual difficult, harmful and monotonous task it was always a human desire. Apart from the various manual, harsh hazardous and monotonous tasks that the robots reaplaced, designing such robots was always a human dream. That was the motive for people to research. The first reference of autonomous machines is appeared on the Homer texts, who described the Hephaestus workplace, which accommodated autonomous tripods and blowers machines. Since the Greek Ancient mythology there are humanoid robots, the giant Talos from bronze as well as humanoid women created by Hephaestus. There are not only mythology references, but also creation of engineers as Filon, Heron of Alexandria etc. These engineers managed to create autonomous machines such as autonomous altars, autonomous temple gates, autonomous coin holders etc.

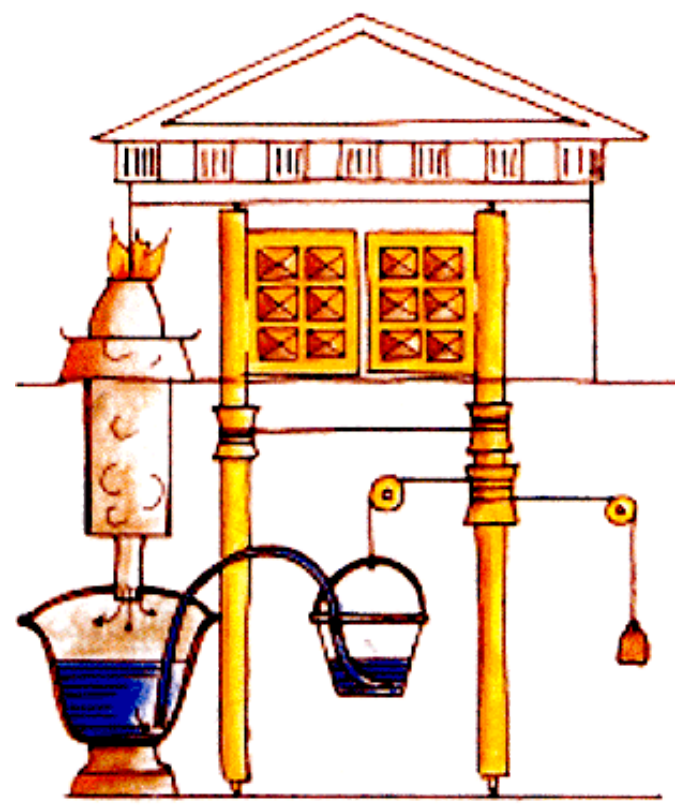

Fig 1: Drawing an automated opening of a temple door

The research of autonomous machines and robots continued in Byzantine era with autonomous music instrument and the most important, the Solomon's throne of Magnaura. That throne could go up and down automatically.

During the Renaissance Period Leonardo da Vinci conducted plenty of researches, the most important of which was the one about how to design a warrior knight. This warrior knight was able to move part of his body, such as the arm, the head and the jaw.

The industrial robots were developed after the beginning of the Computer Numerical Control (CNC). Their creation began with enrichment of mechanisms and actuators as well as with sensors and a "brain" (mostly PCs).

The first generation robots were not able to calculate or sense compared to robots of second generation, which they could program by programming languages and using sensors. The third generation robots deemed intelligent which means that they can make a decision during the execution of their application. Nowadays using computers, the industrial robots 
can control production lines and can easily change their applications.

These days the applications demand work precision, speed, strength and flexibility between several applications. Because of these reasons it's not easy for the people or for engineers to work on these applications. This is the reason why human beings are gradually replaced by the robots. Also the robots could increase the production line, upgrade the quality of the produced products, reduce their rate and apply on dangerous and unhealthy applications. This is one more reason why this scientific field is thriving continuously and rapidly.

\section{Types and categories of robots}

These days robots are applied not only in a variety of processes but also in the researching fields. Depending on the requirements of each application, there are different types of robots which can meet these requirements.

- Fixed-base robots: in this category the base of the robot is fixed on its workspace. The robotic arms are in this category as the robotic arm of this paper.

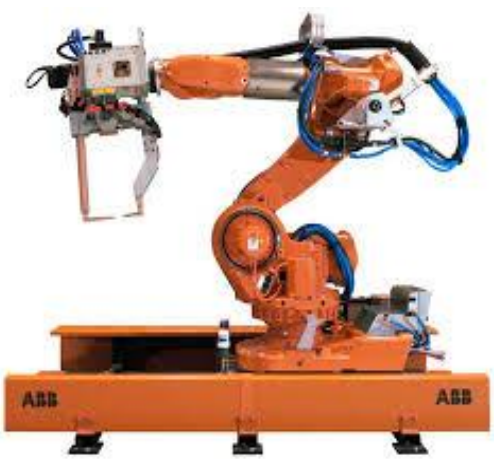

Fig 2: Industrial robotic arm

- Moving robots: the robots of this category do not have a fixed base so they can be moved into their work space. The motion can be done by wheels, propellers, or mechanical legs. Because of that there are more types of robot for this category such as:

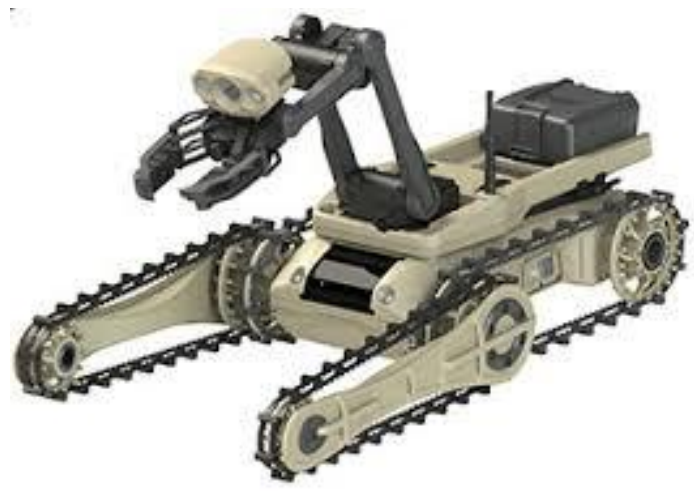

Fig 3: Robot with wheels

- Wheel move robots as in figure 3 .

- Running robots use for movement mechanical leg as the next figure.

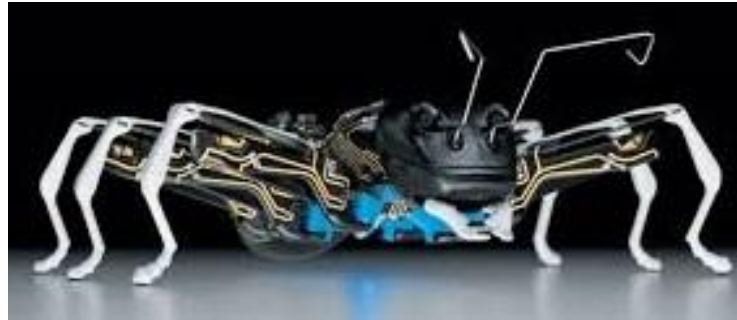

Fig 4: Robot with mechanical legs

- Aerial robots such as drones

- Underwater robots are suitable for underwater operation using a propeller to move.

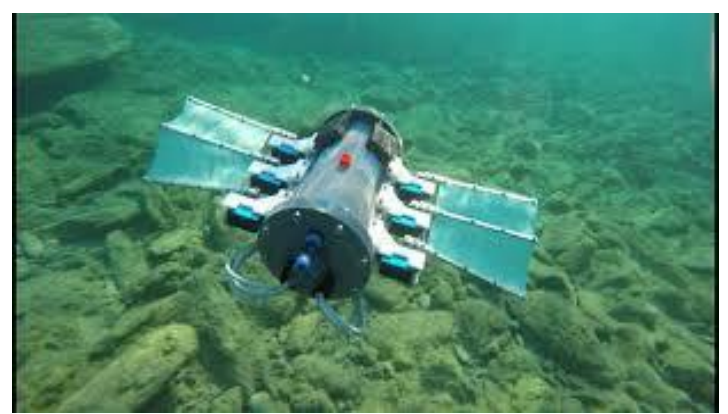

Fig 5: Underwater robot

\section{DESIGN, DEVELOPMENT AND IMPLEMENTATION}

\section{Components}

The robotic arm consists of metal parts for the base and the links, four servo motors MG995 type and one servo motor type JX5521MG. The gear of the servo is metal.

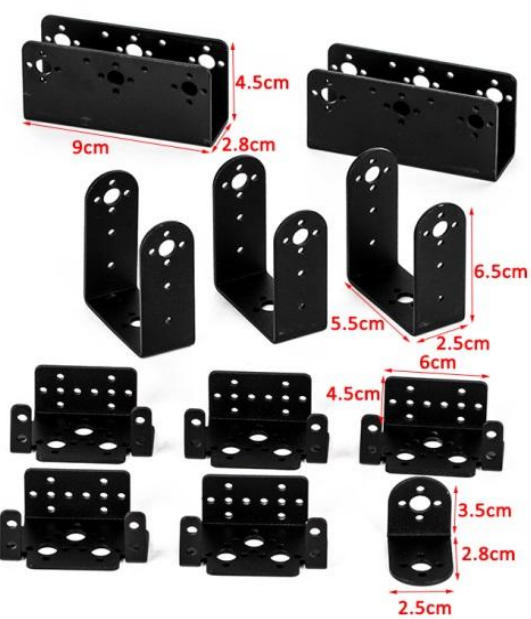

Fig 6: Parts of robotic arm

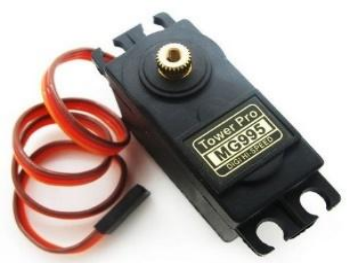

Fig 7: MG995 Servo motor 


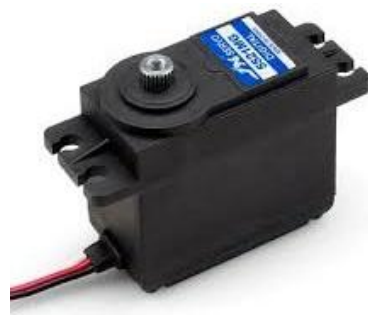

Fig 8: JX5521MG Servo motor

The work space of the arm has two photo resistors, one joystick, three LEDs, three switches, two potentiometers, two buttons and the Arduino in order to control the robotic arm and move the object. The figures below show all of the components.

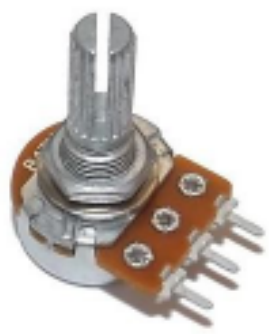

Fig 9:. Potentiometer

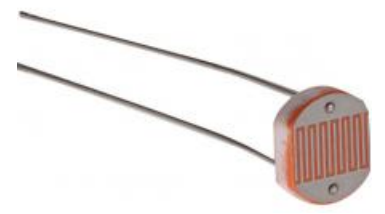

Fig 10: Photo resistor

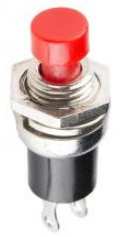

Fig 11: Push button

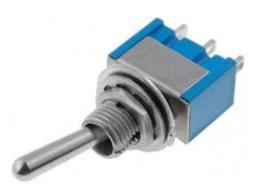

Fig 12: Switch

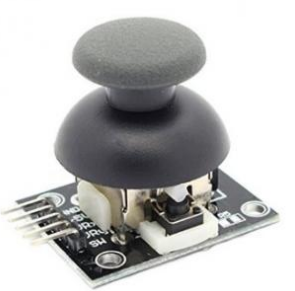

Fig 7: Joystick
The type of Arduino platform used is Uno Rev 3. It has fourteen Digital In/Out Pins, six Analog In/Out Pins and six Power pins. The microcontroller of this platform is ATmega328 and the basic programming language is Wiring. This platform could be controlled by other programs such as Matlab, Labview etc. In addition to this, compiler is easy to use other languages, for example Java, Python, C\# etc. The Arduino Uno contains three kinds of memories: SRAM, EEPROM and Flash.

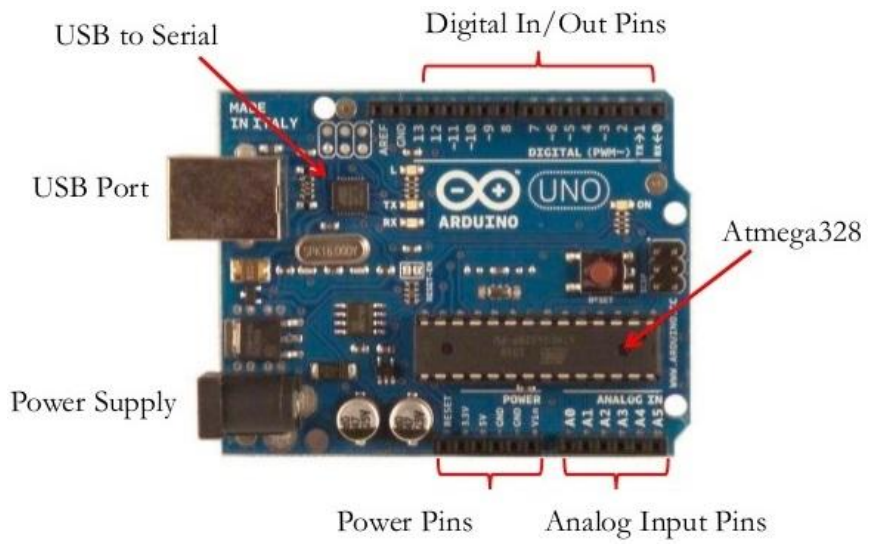

Fig 14: Arduino Uno Rev 3

- $\quad$ The SRAM memory is $2 \mathrm{~Kb}$ and can be used to store any variables, tables, strings etc. We should mention that once the platform cannot provide with power supply the memory resets.

- $\quad$ The EEPROM memory has $1 \mathrm{~Kb}$ space. In this memory we can store data by byte and if the power stops the memory will not reset.

- The Flash memory is $32 \mathrm{~Kb}$, which $5 \mathrm{~Kb}$ is used for the bootloader of microcontroller. The rest of its memory stores the program that the user will give. Flash memory will not reset once the power supply has stopped.

Finally the compiler, programming language and libraries are freely available to all users. This means that people can use program or even learn how to use the platform.

\section{KINEMATICS}

As part of the development and operation of the robotic arm the forward kinematics equations were solved.

In the forward kinematic problem, we investigate the position of the gripper by being familiar with the position and the movement of each joint.

The method of Denavit-Hatenberg was used to resolve the forward kinematics equations. In order to analyze the equations, it is necessary to calculate the coordinate system tables $\mathrm{H}_{0}^{3}$ and $\mathrm{H}_{0}^{1}$

First of all the shift tables are $\mathrm{d}_{0}^{2}=\left[\begin{array}{ll}0 & \mathrm{~L} 1 * \mathrm{cq} 1\end{array}\right.$

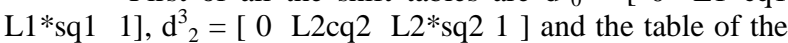
general coordinate system is $S_{A}=\left[\begin{array}{llll}0 & 0 & 0 & 1\end{array}\right]$. The homogeneous transformations table of the coordinate system has the following form: 


$$
\mathrm{H}^{3} 0=\left[\begin{array}{cc}
\mathrm{R}^{3} 0 & \mathrm{~d}^{3} 0 \\
0_{1 \times 3} & 1
\end{array}\right]
$$

For brevity reason, it has been used implemented:

$\mathrm{cq}=\operatorname{cosq}$ and $\mathrm{sq}=\operatorname{sinq}$

Twist tables has the following form:

$$
\begin{aligned}
& \mathrm{R}^{2} 0=\left[\begin{array}{ccc}
1 & 0 & 0 \\
0 & \mathrm{c}_{\mathrm{q} 1} & -\mathrm{S}_{\mathrm{q} 1} \\
0 & \mathrm{~S}_{\mathrm{q} 1} & \mathrm{c}_{\mathrm{q} 1}
\end{array}\right] \\
& \mathrm{R}^{3}{ }_{2}=\left[\begin{array}{ccc}
1 & 0 & 0 \\
0 & \mathrm{c}_{\mathrm{q} 2} & -\mathrm{S}_{\mathrm{q} 2} \\
0 & \mathrm{~S}_{\mathrm{q} 2} & \mathrm{c}_{\mathrm{q} 2}
\end{array}\right] \\
& \mathrm{R}^{1} 0=\left[\begin{array}{ccc}
\mathrm{c}_{\mathrm{q} 3} & -\mathrm{S}_{\mathrm{q} 3} & 0 \\
\mathrm{~S}_{\mathrm{q} 3} & \mathrm{c}_{\mathrm{q} 3} & 0 \\
0 & 0 & 1
\end{array}\right]
\end{aligned}
$$

Thus, the tables of homogeneous transformation of the coordinate system are as follows:

$$
\begin{aligned}
\mathrm{H}^{2}{ }_{0} & =\left[\begin{array}{cccc}
1 & 0 & 0 & 0 \\
0 & \mathrm{c}_{\mathrm{q} 1} & -\mathrm{S}_{\mathrm{q} 1} & \mathrm{~L}_{1} \mathrm{c}_{\mathrm{q} 1} \\
0 & \mathrm{~S}_{\mathrm{q} 1} & \mathrm{c}_{\mathrm{q} 1} & \mathrm{~L}_{1} \mathrm{~s}_{\mathrm{q} 1} \\
0 & 0 & 0 & 1
\end{array}\right] \\
\mathrm{H}^{3}{ }_{2} & =\left[\begin{array}{cccc}
1 & 0 & 0 & 0 \\
0 & \mathrm{c}_{\mathrm{q} 2} & -\mathrm{S}_{\mathrm{q} 2} & \mathrm{~L} 2 \mathrm{c}_{\mathrm{q} 2} \\
0 & \mathrm{~S}_{\mathrm{q} 2} & \mathrm{c}_{\mathrm{q} 2} & \mathrm{~L} 2 \mathrm{~S}_{\mathrm{q} 2} \\
0 & 0 & 0 & 1
\end{array}\right] \\
\mathrm{H}^{1} 0 & =\left[\begin{array}{cccc}
\mathrm{c}_{\mathrm{q} 3} & -\mathrm{S}_{\mathrm{q} 3} & 0 & \mathrm{Lc}_{\mathrm{q} 3} \\
\mathrm{~S}_{\mathrm{q} 3} & \mathrm{c}_{\mathrm{q} 3} & 0 & \mathrm{Ls}_{\mathrm{q} 3} \\
0 & 0 & 1 & 0 \\
0 & 0 & 0 & 1
\end{array}\right]
\end{aligned}
$$

Now we can determine table $\mathrm{H}_{0}^{3}=\mathrm{H}^{2}{ }_{0} * \mathrm{H}_{2}^{3}$

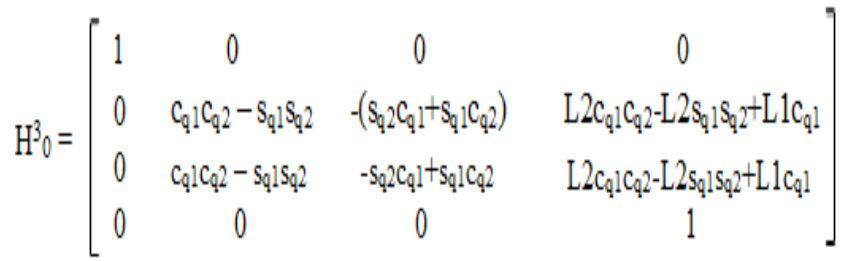

$$
\mathrm{H}^{3} 0=\left[\begin{array}{cccc}
1 & 0 & 0 & 0 \\
0 & \mathrm{c}_{\mathrm{q} 1+\mathrm{q} 2} & -\mathrm{s}_{\mathrm{q} 1+\mathrm{q} 2} & \mathrm{~L} 2 \mathrm{c}_{\mathrm{q} 1+\mathrm{q} 2}+\mathrm{L} 1 \mathrm{c}_{\mathrm{q} 1} \\
0 & \mathrm{~s}_{\mathrm{q} 1+\mathrm{q} 2} & \mathrm{c}_{\mathrm{q} 1+\mathrm{q} 2} & \mathrm{~L} 2 \mathrm{~s}_{\mathrm{q} 1+\mathrm{q} 2}+\mathrm{L} 1 \mathrm{~s}_{\mathrm{q} 1} \\
0 & 0 & 0 & 1
\end{array}\right]
$$

At last the homogenous transformation table $\mathrm{H}^{3}{ }_{0}=\mathrm{H}^{3}{ }_{1} * \mathrm{H}^{3}{ }_{2}$ for movement on all axes is:

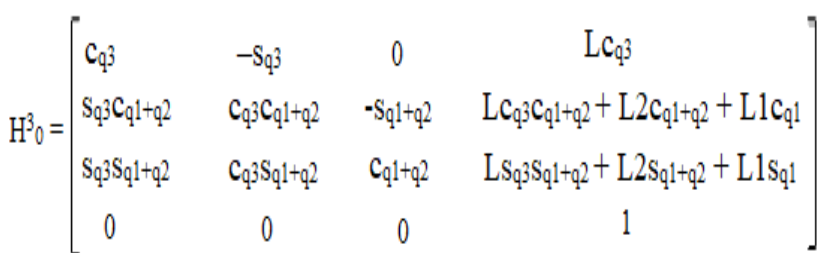

Finally, the table of the generalized coordinates of gripper over to the coordinates of the working space is determined by the following equation $\mathrm{P}_{\mathrm{A}}=\mathrm{H}_{0}^{3} * \mathrm{~S}_{\mathrm{A}}$.

$$
\mathrm{P}_{\mathrm{A}}=\left[\begin{array}{c}
\mathrm{Lc}_{\mathrm{q} 3} \\
\mathrm{Lc}_{\mathrm{q} 3 \mathrm{C}_{\mathrm{q} 1+\mathrm{q} 2}+\mathrm{L} 2 \mathrm{c}_{\mathrm{q} 1+\mathrm{q} 2}+\mathrm{L} 1 \mathrm{c}_{\mathrm{q} 1}} \\
\mathrm{Ls}_{\mathrm{q} 3 \mathrm{~S}_{\mathrm{q} 1+\mathrm{q} 2}+\mathrm{L} 2 \mathrm{~S}_{\mathrm{q} 1+\mathrm{q} 2}+\mathrm{L} 1 \mathrm{~s}_{\mathrm{q} 1}}
\end{array}\right]
$$

\section{OPERATION DESCRIPTION}

Since the arm was not stable during the application. Due to the instability of the arm throughout the application, it has been screwed onto a wooden base.

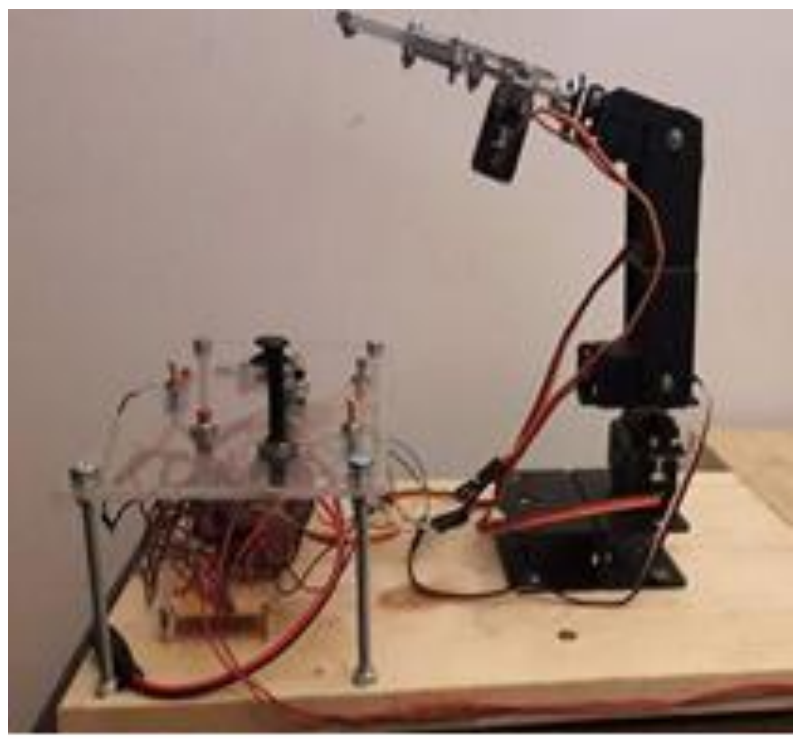

Fig 15: Robotic Arm and Workspace

Also on the wooden base there are screwed the Arduino platform and a panel that was been placed the electrical components, as the figure below.

Using the trigonometric equations $\mathrm{c}_{\mathrm{q} 1+\mathrm{q} 2}=\mathrm{c}_{\mathrm{q} 1} \mathrm{c}_{\mathrm{q} 2}-$ $\mathrm{s}_{\mathrm{q} 1} \mathrm{~S}_{\mathrm{q} 2}$ and $\mathrm{s}_{\mathrm{q} 1+\mathrm{q} 2}=\mathrm{s}_{\mathrm{q} 1} \mathrm{c}_{\mathrm{q} 2}-\mathrm{c}_{\mathrm{q} 1} \mathrm{~S}_{\mathrm{q} 2}$ the $\mathrm{H}_{0}^{3}$ table has the form: 


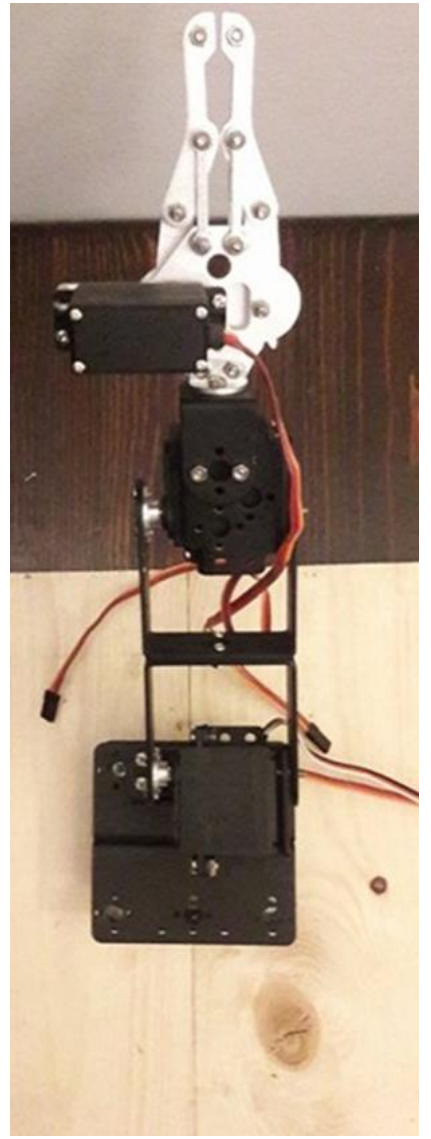

Fig 16: Robotic Arm

The photo resistors have been placed at the edges of the base. When the arm is in automatic mode it transfers the object from one end to the other, depending on the input data of each photo resistor. A three-position switch is set as a switch to enable the automatic or manual operation. This means that when the switch is turned in automatic mode the robotic arm will move the object between the two points that are the photo resistances, continuously until the operating signal is interrupted.

During the manual mode, users can move the servos on the base of the robotic arm with a joystick. The elbow of this servo is controlled with a potentiometer and the servo of the gripper is controlled by a push button. Another potentiometer manipulates the speed of all servos. Also the user with a threeposition switch can initiate the storage of random positions of the robotic arm into processor's SRAM memory or instruct the processor to move the robotic arm at saved positions in the order they are assigned.

\section{CONCLUSIONS}

During the work we studied the implementation stages of a robotic arm. The low cost, the performance, as well as the impact of the robotic arm on future additions were some of the most essential factors considered before conducting this paper work. In its present form, the arm can perform various functions depending on the type of the final process tool. In conclusion the robotic arm at this primary form can be used as a simulator in order to help the user understanding how industrials robots or prosthetic robotic arms could build and operate.

\section{ACKNOWLEDGMENTS}

All authors would like to express their gratitude to the Piraeus University of Applied Sciences for providing the required data and funding in order to undertake and complete this research project as part of "Industrial Automation" Postgraduate Program of Studies.

\section{REFERENCES}

[1] Chatzigiannakis The $\mathrm{C}++$ language in depth, Publications Kleidarithmos, Athens 2011

[2] http://apothesis.teicm.gr/xmlui/bitstream/handle/1234567 89/814/sefi.pdf?sequence $=1$

[3] https://apothesis.lib.teicrete.gr/bitstream/handle/11713/75 64/SmaragdakisEmmanouil_XoustoulakisKonstantinos2 016.pdf?sequence $=3$

[4] http://okeanis.lib.teipir.gr/xmlui/bitstream/handle/123456 789/1700/aut_00550.pdf?sequence=

[5] http://okeanis.lib.teipir.gr/xmlui/bitstream/handle/123456 789/1601/aut_00467.pdf?sequence=

[6] https://www.doc.ic.ac.uk/ zf509/Publications/2nd_Natio nal_Convention_of_ECE_Students.pdf

[7] https://www.arduino.cc/

[8] https://forum.arduino.cc/

[9] https://el.wikipedia.org

[10] https://servodatabase.com/servo/towerpro/mg995 